Resumo

Nesse trabalho, a partir da perspectiva da Psicanálise e Educação, abordaremos as cerimônias minimas como dispositivo aceito para a intervenção e a pesquisa clínico-social, operador metafórico que nos permite criar condiçoes de possibilidade subjetivantes em diferentes cenários sociais, escolares, institucionais, comunitários.

Descritores: psicanálise; educação; práticas socioeducativas.

\section{CERIMÔNIAS MÍNIMAS}

\author{
Mercedes Minnicelli
}

\section{Introdução}

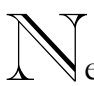

1 esse trabalho abordaremos as cerimônias mínimas como um dispositivo adequado para a intervenção e a investigação clínico-social, um operador metafórico que nos permite criar condições de subjetivação em diferentes cenários sociais, escolares, institucionais e comunitários.

Consideramos esse tema em tempos turbulentos para pensar a socialização e a educação das novas gerações. Tempos em que a violência se manifesta em toda parte de forma "pura", sem um fim e sem sentido. Tempos em que as novas gerações refletem especularmente o mundo em que vivemos e tornam-se eco - e carne - dessas perspectivas, que, pretendendo ser silenciadas, operam suprimindo a subjetivação.

A partir de algumas vinhetas interessa-nos ilustrar como é possível fazer com que o dito fale, re-

Psicanalista. Doutora em Psicologia. Diretora da Rede Interuniversitária Interdisciplinar INFEIES (Estudos e Pesquisas psicanalíticas e interdisciplinares em Infância e Instituição(es). Docente e pesquisadora da Faculdade de Psicologia da Universidade Nacional de Mar del Plata - Argentina. 
criando novas significações e uma mudança de posição dos adultos em e pelas "cerimônias minimas", frente aos ditos - e feitos - que se apresentam cotidianamente em diversos cenários (educativos, sociais, jurídico-institucionais).

Sabemos que as causas de certas formas de apresentação do mal-estar contemporâneo são muitas e variadas, e não podem ser determinadas pela simples relação linear de causa e efeito. É por isso que, em vez de nos debruçarmos sobre as causas, nesse trabalho, a partir de uma perspectiva psicanalítica, interessa-nos a promoção de efeitos socioeducativos possíveis, especialmente nos tempos em que estamos imersos (e conosco, nossas crianças e jovens) em uma "festa" social, cultural e econômica, presidida por um discurso generalizado que promove o sem-limites-como-força-de-leisem-lei.

Quando operamos um recorte e nos detemos em um dito ${ }^{2}$ que enuncia um mal-estar, estamos pontuando o devir do discurso, ao delimitar um enunciado que nos permite produzir operações discursivas frente ao que se repete sem cessar e sem ser registrado, nem escutado, tanto pelo desconforto que gera, como pelos efeitos de-sujetivantes que produz. A operação discursiva é possível se se faz do dito, outros dizeres. A pergunta é a chave que habilita operações de linguagem.

A expressão do mal-estar nos fala de adultos, muitas vezes perplexos, sejam eles professores ou especialistas, também corre o risco de recorrer a fórmulas pseudocientíficas mercantis para silenciar o que ferve pulsionalmente de modo descontrolado, limitado apenas por ações. Perplexidade que inibe a possibilidade de fazer algo diferente com o que parece de abordagem duvidosa, caindo na armadilha de um círculo vicioso que nos interessa e podendo sofrer a interferência de cerimônias minimas criadoras de condições de possibilidades subjetivantes.

Os ditos que enunciam o mal-estar expressam que ali mesmo está o porfazer-se, que sempre parte do questionamento do estabelecido, permitindo o jogo significante e a criação de outras alternativas que contam com fundamentos teóricos da psicanálise e que se nutrem da contribuição de outras disciplinas sociais. As vinhetas clínicas que apresentamos nomeiam o mal-estar. Foram recortadas em nossas experiências clínico-institucionais, por meio das quais identificamos efeitos socioeducativos possiveis, promotores da sustentação do laço social. 
Nossas pesquisas e experiências dão-nos claras provas do modo com que esse possível se habilita ao oferecer alguma forma de resistência ao que se apresenta como inexorável. Reforçamos a ideia freudiana sobre o impossível de educar, analisar e governar, ou seja, ainda que não possamos garantir os resultados antecipadamente, por si só e sem garantias, não podemos renunciar à tarefa de educar, analisar e governar.

Trata-se de reestabelecer o après-coup da experiência, a análise posterior, sua reconstrução minuciosa, sua narrativa em diálogo com os outros, para encontrar pistas significantes, formas discursivas repetidas que nos indiquem o caminho que permite a pergunta.

A partir dessa posição, consideramos o que acontece como contingente e não necessário, levando-nos à revisão de nossas práticas cotidianas, as mais repetidas, as mais óbvias; aquelas que, por estarem tão incorporadas ao cotidiano, ao repetirem-se, passam quase despercebidas. Trata-se de criar dispositivos que permitam operar sobre as condições, em cada caso, de produção de certas respostas de crianças e adolescentes.

\section{Cerimônias mínimas: sua qualidade de dispositivo}

Lacan (1995) situa o dispositivo com relação à metáfora ao considerá-la um dispositivo para pensar:

Percebem, sem dúvida, que estou esquematizando, mas o desenvolvimento de uma metáfora, de um dispositivo para pensar, exige primeiro entender para o que serve. (p. 129)

Pensar em um dispositivo tal como Lacan a ele se refere nos leva a uma metáfora que nos convida a pensar no fazer a partir do dito e do feito.

Denominaremos cerimônias minimas o dispositivo clínico-metodológico, sinal e chave para múltiplas intervenções possíveis. Servimos-nos delas mais do que como um conceito que admite uma única definição, mas como uma metáfora, isto é, um dispositivo para habilitar alternativas de intervenção não-convencional.

As cerimônias mínimas, como metáfora, resultam da escuta ativa de uma forma discursiva que se recorta, circunscreve-se e pontua em função do dito e dos fatos. 
Se nos permitimos questioná-los, qualquer dito, assim como qualquer fato, admite, por sua condensação, diversas vias de análise e pesquisa. As cerimônias mínimas são um marco simbólico que é perfurado pela pergunta que o interroga, causando uma hiância, um vazio, um "entre" o dito e o não dito, entre o dito e o feito, entre os feitos - geralmente desalinhavados, para dizer e promover outros enlaces discursivos, isto é, novas formas de dizer e de fazer que delas derivem.

O que dizem as cerimônias mínimas? O que dizemos com elas? Avancemos na abertura discursiva da metáfora.

\section{Cerimônias}

Em primeiro lugar, devemos buscar as definições de cerimônia para, em seguida, situar as cerimônias minimas como uma instância que nos permita operar com as situações que se apresentam como fechadas, encapsuladas em fórmulas discursivas que enunciam o mal-estar que se inscreve e interroga.

Desenvolver o conceito de cerimônia leva-nos a fazer associações com o mito, o rito e o jogo (Agamben, 2003), para chegar a expor as cerimônias minimas, objeto de nosso interesse, a partir de uma extensa gama de possibilidades.

O dicionário da Real Academia Espanhola define "cerimônia"3 como:
"Ato solene realizado de acordo com normas ou ritos estabelecidos".

As cerimônias se associam aos rituais próprios das comunidades e suas instituições, sejam elas religiosas, jurídicas, educativas ou governamentais. Do mesmo modo, as festas, como por exemplo, o Carnaval, implicam em formas cerimoniais, especialmente ligadas ao rito, ao ritual, à celebração, ao ato, ao cortejo, à solenidade, à investidura.

O substantivo que define a cerimônia é "ato".

O que é um ato ? Continuando com o dicionário da Real Academia Española, é um feito ou uma ação, fato público ou solene, a divisão importante de uma peça teatral e, em Direito, uma disposição legal.

Ritos e rituais têm circunscrito, ao longo do tempo, momentos de passagem - de diferença - entre nascimento e morte, metáforas de qualquer início e finalização. Diferenças entre "estados" - da infância à juventude -; diferenças "entre" estar ou não estar iniciado na sexualidade adulta. A partir dos Estados Modernos, as diferenças de "estado civil" pela cerimônia de casamento civil, entre outras - outrora exclusivamente religiosa -; diferenças "entre" contar com a possibilidade de estar inscrito na sociedade pela inscrição, no registro civil, de cada novo nascimento / morte. Ainda que à primeira vista não assumam a forma convencional de rituais, é possível identificar restos dos 
mesmos em seus procedimentos normativos; basta analisar as disposições administrativas que estabelecem de que modo devem se realizar tais procedimentos. Assim, permitimo-nos chamar de formas cerimoniais jurídico-administrativas os "circuitos de intercâmbio legitimadores" - segundo o conceito de Bourdieu (1985) próprios da burocracia.

As formas cerimoniais circunscrevem um marco simbólico normativo e têmporo-espacial para o desenvolvimento da cena cujo roteiro será diferente dependendo da instituição e dos objetivos da mesma.

Ou seja, uma cerimônia apresenta um formato, embora seus fundamentos nem sempre sejam explícitos no roteiro normativo e no texto do drama que aí se desenrola. Por sua vez, em todos os casos se encontram personagens que desempenham papéis determinados ou criados ad hoc, os quais podem ser múltiplos e variados.

Aquilo que identificamos como invariante é que toda forma cerimonial apresenta um tempo de abertura, desenvolvimento e encerramento. De alguma forma, preservando a lógica ritual, pela cerimônia é "criado" um tempo que se suspende para marcar outro tempo, o do início e o do final, o das novas condições sociais investidas - "criadas" - pela passagem que a mesma institui.

Em toda cerimônia se "jogam" - isto é, se atuam, se representam diferentes papéis ou posições sociais 
encarnadas por aqueles socialmente investidos para desempenhar o papel escolhido ou atribuído.

Nossa vida diária social e institucional apresenta múltiplas formas cerimoniais, e muitas delas tão naturalizadas (burocratizadas) que exigem um trabalho de desconstrução para sua identificação. Pensemos naquelas mais íntimas, as que repetimos diariamente em nosso cotidiano, que serão diferentes para cada indivíduo, para cada grupo familiar. Há cerimônias próprias de ambientes educacionais quando se realiza a abertura do ano escolar ou quando ocorre seu encerramento; cerimônias de celebração, cerimônias de homenagem; de passagem de ano, de formatura, nos mais diferentes níveis de ensino... A lista está aberta para que cada um a continue. Consideremos um processo que, para muitos, pode ser familiar: "obter a carta de motorista", que também tem seu formato, seu roteiro normativo, seus representantes sociais e que se finaliza com a entrega de um documento que identifica, frente a terceiros, que se está "habilitado ou não" para dirigir.

Ao contrário das cerimônias e formas sociais de certos animais que foram estudados pelos etólogos, a capacidade de criar suas próprias cerimônias é algo que pertence à cultura, sendo, portanto, inerente aos seres humanos e implicando, em todos os casos, um ato, um marco, um roteiro (nas sociedades modernas especificamente o sistema jurídico-insti- tucional) e determinando uma posição temporo-espacial que as sustenta aí por sua repetição.

Esse quadro temporo-espacial não é necessariamente definido pelo relógio, mas toda vez que..., antes que... ou depois de... outros fatos. Enquanto a forma cerimonial delimita, legisla o tempo, estabelece um ritmo, é possível que aí mesmo esse tempo fique suspenso. Enquanto circunscreve um cenário, cria um marco para o desenvolvimento da cena e para a suspensão do tempo.

O relato de um conto "antes de... ir dormir" é um claro exemplo do efeito de una cerimônia mínima que fixa o tempo e, também, que o coloca em suspenso pela expressão "era uma vez...", regressando depois ao tempo ordinário com “... esta história entrou por uma porta e saiu pela outra, quem quiser que conte outra..." passagem que a cerimônia acompanha é o da vigília ao sono, criando o marco para a cena subjetiva. As crianças pequenas e aquelas mais debilitadas, subjetivamente falando, apelam à repetição: "conta de novo..."; elas pedem e exigem que a dita reiteração seja fiel ao original, "não era assim... não mude...”, queixando-se das variações que desestabilizam a repetição.

Devemos fazer uma reserva. Falar de repetição em psicanálise nos conduz a "Além do princípio do prazer" (Freud, 1920/1995), momento crucial da teoria em que Freud outorga dois lados à repetição: de um lado, a repetição compulsiva; de outro, o 
jogo do fort-da. No primeiro caso, o sujeito é capturado de forma passiva por "algo" que ele vive como uma obrigação, como forçade-lei-sem-lei ou que o obriga a agir, mesmo às suas custas e com prejuízo. No segundo caso, o autor pode transformar ativamente seu sofrimento - sujeito à legalidade da linguagem, ele transforma os fatos com a mobilidade significante que o jogo torna possível. Um pai terrível pode tornar-se um leão faminto que caça suas presas, e um ratinho pequeno e travesso poderá assustá-lo e fazê-lo fugir, saindo triunfante frente ao que antes o fazia sentir-se desvalido.

No entanto, seguindo os dois lados da repetição, por uma delas as cerimônias mínimas nos indicam que tanto podem cristalizar, encapsular e naturalizar os fatos que acontecem - adquirindo formas ritualizadas - como deixar sem sustento algum a compulsão à repetição. Sua outra face fala de uma outra via possível, que queremos enfatizar: aquela que habilita a lógica do jogo, implicando um fazer ativo simbólico-imaginário com o real da experiência.

Em um extremo, as cerimônias, por seus rituais, tornam-se um esteio das tradições quando a repetição protocolar as naturaliza, estabelecendo-as como tais, reiterando uma e outra vez o mesmo protocolo sem interrogação alguma. Além disso, embora o ritual defina o mesmo para sempre, o drama subjetivo se encarregará de encontrar as diferenças e as rachaduras. Os celebrantes de tradições ritualizadas punem as mudanças, não toleram a estrutura flexível, pretendem que sempre o mesmo apareça e garanta a estabilidade procurada. As tradições, nesse sentido, buscam a estabilidade permanente, sem variações, sem espaço para as transformações. Nesse caso, a conservação da instituição está acima dos sujeitos implicados.

$\mathrm{Na}$ mesma direção, ainda que seja seu oposto, encontra-se o caso que se apresenta sem qualquer referencial. Abolido qualquer padrão de referência, o sem limite adquire força de lei-sem-lei, ficando de tal modo entregue a seu ponto absoluto que dilui qualquer ancoragem. Um exemplo do extremo dessa condição pode ser encontrado quando, em uma luta corpo a corpo, a violência evolui de modo desenfreado até a morte de um ou de outro, único limite para o desenfreado ${ }^{6}$.

Os efeitos de ambas as posições localizadas na mesma polaridade não deixam de ter consequências subjetivas. 


\section{Cerimônias mínimas}

O reconhecimento do que podemos identificar como cerimônias mínimas resulta da escuta de um dito, um fato ou uma ação que recortamos nos dispositivos $^{7}$ institucionais e sociais, seja para sua interrogação ou análise - quando o repetido se encontra naturalizado e criptografado; ou porque queremos criá-la, isto é, instalá-la para promover uma interferência, uma interdição, um corte no estabelecido, esperando que se operem outros enlaces discursivos.

Nos casos que apresentamos, é possível observar de que modo se conservam as marcas de uma obra cênica (embora não seja uma obra teatral) e que, por sua vez, apresentam o caráter e a eficácia simbólica de uma disposição legal que por seu intermédio se cumpre com força-de-lei-sem lei, embora efeito de discurso que situa a lei como operador da estrutura.

O atributo "mínimas" confere um caráter diferencial ao termo cerimônia, afastando-a de suas definições gerais, mas mantendo seus traços mais significativos. Não se trata de grandiloquência, nem de solenidade, mas da institucionalização, da escrita de pequenos atos que conservam as características próprias das grandes cerimônias - embora passem inadvertidas na vida cotidiana, é a elas a que devemos nos referir.

$\mathrm{Da}$ solenidade que se confere às cerimônias em geral, ficaremos com 
o que implica dar importância, atribuir valor, investir como ato significativo os atos cotidianos dos cenários educativos, sociais, judiciais como instâncias chave de produção de subjetividade.

As cerimônias minimas não se definem pelo tamanho, nem pela importância de um ato, mas, ao contrário, trata-se de outorgar aos pequenos atos o caráter de grandes ações que vão se enlaçando entre si, gerando novas redes discursivas e fatuais.

Em nossa metáfora fazemos referência, por um lado, ao que Foucault (1989) denominou como microfísica do poder e, de modo substancial, à psicanálise, ao considerar as ressonâncias singulares e os efeitos do discurso coletivo na singularidade. Nenhum discurso poderia ser eficaz se não fosse pela ancoragem singular, pelos efeitos de identificação - como os da massa - que se operam pela imersão no universo linguístico social, isto é, pela imersão no discurso que veicula a linguagem. Um exemplo claro disso é um chiste traduzido de outra língua. Um relato será um chiste e nos fará rir se operar de maneira inconsciente, se "nos tocar", se identificarmos aquilo que por ele se diz.

Estabelecemos um duplo caráter das cerimônias mínimas, que iremos analisar e ilustrar por duas vinhetas: "Os bebês se amotinaram" e "Se eles escondem os cadernos de comunicações, com certeza serão delinquentes”.
Sustentaremos que a criação e implementação de cerimônias mínimas estão propensas à promoção de condições de possibilidade subjetivantes em que o limite se apresenta como um abismo. Conceder a ele o caráter de criador de condições subjetivantes implica necessariamente entender que o poder (fazer) não se localiza exclusivamente nas grandes estruturas, mas que se suporta em mínimos detalhes, na palavra, no discurso diário, na posição de cada sujeito na relação com os outros.

As cerimônias mínimas como instância de intervenção implicam em um reposicionamento subjetivo dos adultos diante de meninos, meninas e adolescentes. Nesse sentido, sublinhamos o quanto, por meio delas, foi possível medir a distância do macrossocial, que tem como efeito impotência e incapacidade para lidar com a complexidade de variáveis que atacam as condições de subjetivação, recuperando margens possíveis de intervenção docente e profissional, resgatando as possibilidades de sujeição do humano à cultura, fazendo do dito, outros dizeres.

As cerimônias mínimas envolvem a possibilidade de escrita da lei na trama social. Trata-se de restituir a legalidade no lugar em que uma pura força-de-lei-sem-lei age como se fosse necessária e obrigatória. A "obrigação" que leva à ação pode se dar às custas do sofrimento dos sujeitos envolvidos. Sustentamos que, mesmo no limite, é possível restaurar condições 
de dignidade e respeito para cada um e para os outros no laço social.

Em síntese, nossas hipóteses enunciam:

1) Institui-se um discurso em e pelas cerimônias minimas;

2) Desarticulam-se discursos criptografados em e pelas cerimônias minimas;

Passemos a ilustrá-las.

\section{Institui-se um discurso em e pelas cerimônias mínimas:}

“Os bebês se amotinaram!!!”

No berçário de um lar provisório de um município de General Pueyrredón (Província de Buenos Aires), ouvem-se os sons de chocalhos com uma intensidade inusitada. Há doze bebês na sala que, nesse momento, estão em seus berços após acordarem de uma soneca. Confrontado com este alvoroço, o chefe da área, que estava em outra sala, vai para o berçário e observa que, enquanto as enfermeiras estavam fazendo a troca de fraldas de duas crianças, os outros bebês - de 8 a 13 meses de idade - estavam em pé em seus berços batendo o chocalho firmemente contra a parede. Os adultos presentes ficaram para observar a cena, comentando com um tom de humor, surpresa, ternura e um toque de espanto: os bebês se amotinaram!

"Como os presos na cadeia" é a primeira associação de todos aqueles para quem que relatei este evento. Esta cena, ao ser questionada e analisada nos dias seguintes, retornou algumas vezes pela pergunta: qual é o 
lugar que se outorga a essas crianças por estarem imersas no discurso de "minoria"?

Os termos que nomeiam os laços sociais da minoria seguem a linha dos códigos carcerários, assinalando um destino inefável. O fato de ser órfão, ou abandonado, é uma condenação? Um insulto? Uma marca negra desde muito cedo? Ou uma condição filial não escolhida pelos pequenos que requer do Estado, da representação social de maneira substantiva, a criação de outras condições familiares quando a família biológica não é viável?

A leitura desse incipiente fenômeno de laço social e demanda coletiva em uma idade demasiado precoce admite outras leituras além daquela que os associa à minoria. Para essas crianças, os espelhos em que se olham refletem múltiplos olhares e não o retorno especular da própria imagem sustentada no olhar materno. Na falta deste, é necessário que haja algum olhar no qual se refletir.

Significar esse ato como "motim" não deixa de ter consequências para sua localização no tecido das relações sociais. As mamadeiras não chegavam a tempo. Motim? Ou protesto expresso em um jogo de imitação com o prazer pelo som produzido? Reação especular?

Identificamos nesta cerimônia mínima o momento da criação de personagens da Novela social de la infancia desamparada (Minnicelli, 2004).
Pierre Legendre (1996), na introdução de $O$ inestimável objeto da transmissão, convoca-nos a uma profunda reflexão:

Devemos lembrar que as instituições são um fenômeno da vida. Evocar a vida seria uma banalidade se não se tratasse aqui de manipular a questão jurídica, que está tão mal em nossos dias. Uma característica faz do humano algo à parte no ser vivo: a palavra. Instituir o ser vivo é um fato de discurso, supõe a humanidade. A humanidade, então, deve ser definida como o vivo falante. (p. 10)

E acrescenta mais adiante: "Isto é o que está em jogo na escala social: esmagar a vida ou fazê-la viver" (p. 10).

Mínimas expressões inclinam a balança para o achatamento da vida, ou para fazê-la viver.

\section{Desarticulam-se discursos criptografados em e pelas cerimônias mínimas:}

Sabemos bem que nas últimas duas décadas, múltiplos e diferentes Programas, Centros de Estimulação Precoce, Lares, Clubes, Sociedades de Fomento, Fundações e ONGs, bem como a sanção da Lei Nacional de Proteção de Direitos no 26066 (2005) e os Centros de Proteção de Direitos têm tomado a iniciativa frente à ausência do Estado no desenvolvimento de tarefas relativas à educação, so- 
cialização e tratamento dos problemas que afetam os meninos, meninas e os adolescentes em nosso país.

Apesar disso, ainda não se visualizam mudanças significativas em termos gerais; a sensação é que nada produz os efeitos proclamados pelas boas intenções, o que ocorre principalmente quando um desses cenários não se situa como elo de uma rede discursiva mais ampla, mas como centro de atenção ou de ação prioritária, desconhecendo a importância dos outros, inclusive da escola.

Passemos a um caso por meio do qual podemos ilustrar de que modo é possível identificar o que promoveu uma troca de posição dos adultos frente às crianças, por uma cerimônia mínima que produziu efeitos socioeducativos. Esta vinheta é interessante para pensar a circulação da interrogação e a palavra que permite, frente ao fato, habilitar outras alternativas que considerem o outro. Ao mesmo tempo, vemo-nos diante da apressada e cômoda leitura "dessas crianças" como transgressoras geneticamente determinadas, quando, na realidade, estão apenas respondendo à demanda do Outro (Minnicelli, 2010).

\section{"Se eles escondem os cadernos de comunicações, com certeza serão delinquentes"}

Durante o ano de 1998, docentes de uma das escolas que dava assistência a crianças de um lar de acolhimento expressaram sua queixa por não receberem resposta para as repetidas notificações enviadas nos cadernos de comunicações sobre dificuldades que se apresentavam na escola.

Como não recebiam do lar de "internação" - como o chamavam - nenhuma resposta, as professoras comunicaram-se por telefone, furiosas com a diretora do mesmo, dizendo que não apenas não obtinham resposta para suas reclamações, mas que as faltas cometidas pelas crianças deviam ser sancionadas. A diretora diz desconhecer as comunicações e as sucessivas reclamações a que elas se referiam.

Pediam dupla sanção para as crianças, por um lado, diante da falta de cumprimento do requisito escolar, e, por outro, pelo fato de que os menores escondiam seus cadernos e não os entregavam aos responsáveis do lar. 
Diante do fato e dos ditos de uma e outra parte, a pergunta chave é: o que levava as crianças a esconderem os cadernos? Seria sua condição de menores morando em um lar a "causa" do fato? Temeriam ser punidos e, por isso, não entregavam seus cadernos? Quais eram as faltas que as notas transmitiam?

Ao serem questionadas, as crianças disseram não saber porque escondiam seus cadernos, mostrando-se indiferentes ao assunto que tanto reboliço produzia entre os adultos.

Ler os cadernos de comunicações para atender às demandas das professoras e saber quais eram as faltas às quais elas se referiam apresentou-nos uma chave interessante. Uma expressão mínima dizia o óbvio sobre que estava acontecendo, sem ser visto, nem lido: cada uma das notas estava dirigida aos "Srs. Pais", ou, "Papais", ou à "Sra. Mamãe", e falavam sobre a não realização de tarefas, da presença nas aulas sem os materiais solicitados, ou ainda sobre o fato de se apresentarem na escola desarrumados, despenteados e sujos.

Lembremos que a falta cometida pelas crianças era a de esconder os cadernos de comunicações?. Convido-os a observar o gesto de esconder os cadernos, que nada mais fazia do que enunciar uma verdade: os "Srs. Pais", "Papais", ou a "Sra. Mamãe" não estavam presentes para receberem o caderno diariamente, sem metáfora, mas à letra. Eles os guardavam, indiferentes, fazendo com que as no- 
tas, literalmente, não chegassem a ninguém. Os destinatários a quem os adultos se dirigiam não estavam presentes. A questão foi abordada e abriu diversas vias de análise; tornou-se claro um certo lugar atribuído a elas por serem "menores internados", em uma falsa associacão com "menor, filhote de delinquente".

Diante dessa constatação, foi proposta uma reunião com todos os adultos que, de uma forma ou de outra, cuidavam das crianças: os preceptores e a direção do lar de residência (não de internação), assim como os professores e diretores das escolas, clubes, oficinas, o padre do bairro, os médicos do centro de saúde forma convocados para analisar o tema que excedia o problema de uma suposta indisciplina em torno do fato ligado aos cadernos de comunicações, mostrando o lugar que as crianças tinham no discurso generalizado sobre sua condição de menores "internados" em um lar.

Ainda que se apregoasse um prognóstico desfavorável a respeito da acolhida que teria tal convocação, os fatos disseram algo diferente. A reunião foi multitudinária, provocando um impacto, dado o número de pessoas vinculadas a eles de maneira cotidiana.

Analisou-se o problema do que poderia implicar o fato de as notas serem dirigidas ao ponto mais traumático, de maior sensibilidade e dor para as crianças. A ausência dos pais havia promovido a decisão de inter- venção judicial, de modo que seu local de residência - ainda que transitório, em muitos casos - fosse um lar de acolhimento. Foi levantada a questão chave de que a socialização das crianças estava em cada ato realizado por todos os que, de uma forma ou de outra, intervinham diariamente com eles. Novos dizeres foram surgindo, novas alternativas, novas formas de tratar sua socialização. Por exemplo, surgiu algo inédito - sobre o que fazer com os aniversários. Não havia convites, porque pensavam tratar-se de um lugar de confinamento. Então, os colegas da escola começaram a frequentar o lar e as crianças começaram a ser convidadas para os aniversários de seus companheiros.

Especificamente em relação aos professores, e a todos aqueles que, de uma forma ou de outra, quissessem transmitir algo por escrito aos adultos de quem eles dependiam, foi concebido um novo esquema de circulação das notificações. As crianças não tardaram a mostrar em atos o impacto desta mudança. A destinatária das notas seria a diretora do lar, por ser a pessoa que tinha maior estabilidade horária e a responsabilidade de administrar o material, permissões e recursos que pudessem ser requeridos pela escola e outras instituições para limitar qualquer burocracia.

Esta pequena, mas grande mudança, transformou a disposição das crianças ao encontrarem não somente a quem entregar os cadernos todos os dias ao retornar da escola ou de suas 
outras atividades, mas a possibilidade de terem com quem falar do assunto; facilitou-se assim o processo de levar os materiais solicitados, a avaliação das permissões e as questões de saúde, entre outras questões cotidianas, que antes permaneciam sob silêncio.

As anotações do caderno de comunicações continham palavras que refletiam, por meio de mínimas expressões, o imaginário sobre as crianças, idealizações sobre suas famílias e montagens institucionais organizadas num circuito fechado de exclusão, sustentando suposições sobre "a minoria sem possibilidades de educação".

A leitura da indisciplina do ato cerceava as possibilidades de dar espaço para outras significações. Do ponto de vista das crianças, não se tratava só de entregar os cadernos como um castigo, nem para serem fiscalizados, mas para ter alguém a quem contar o que aconteceu no dia, as dificuldades e os êxitos, obtendo assim uma maior disposição dos recursos como parte das pequenas coisas do dia-a-dia institucional em conversas com o outro, disposto a ouvir e a falar com eles, habilitando-se assim uma outra circulação discursiva possível.

Dirigir as notas para quem possa recebê-las, lê-las e falar a partir delas, é habilitar uma via de intercâmbio, antes fechada, pois os destinatários estavam ausentes.

Ilustramos assim de que modo uma cerimônia mínima pode ser um veículo de conservação do "sempre foi assim", e também, por sua análise, de que modo é possível abrir o jogo, gerar outras ações que permitam uma interferência sobre o dado e cristalizado. O que é disposto pelo dispositivo se dissolve a partir de uma cerimônia minima que promove uma nova disposição para a escuta dos outros, cujas repercussões podem nos surpreender.

\section{Cerimônias mínimas, mals uma vez...}

Os ritos, rituais e cerimônias gozam de profundo desprestígio em nossos tempos, nos quais a liquidez, a fluidez e o sem limites ficam ligados, indistinguíveis e descontextualizados inclusive do objeto de análise do autor.

Neste entorno argumentativo, pouco favorável à instituição de marcos simbólicos, reiteramos o lugar significativo que podem ter 
as cerimônias minimas, consideradas tonto como unidade de análise em nossas pesquisas, como pela sua capacidade de intervenção e interferência em uma dupla via: a) referente a ritualizações criptografadas; b) no que diz respeito ao sem limite, ao indiferenciado.

Ao mesmo tempo, constatamos de que modo, por meio das cerimônias minimas pode operar-se o estabelecimento de condições de realização da interminável tarefa de fazer do dito e do feito outros dizeres e fažeres. Este ponto é relevante, especialmente em relação à suposição da abolição das cerimônias e rituais; na abolição da lógica do ritual em supostos tempos de fluidez e desinstitucionalização, segue-se essa tendência sem um questionamento que a detenha, e é o mercado que ritualiza e impõe suas próprias liturgias, gerando desconcerto e uma ilusão de liberdade que só alimenta a onipotência, a descrença e a voracidade humana (Minnicelli, 2010). (1992):

A propósito deste assunto, sublinhamos a citação de Lacan

Se durante muito tempo o homem acreditou que seus ritos, suas cerimônias, fossem indispensáveis para manter as coisas no seu lugar, o limite foi transposto quando o homem percebeu que seus ritos, danças e invocações, na verdade, nada tinham a ver com essa ordem. (p. 440).

Os ritos, bem como os dispositivos e as instituições, são artificios não naturais. O que caracteriza um rito, em sua repetição, é a estabilidade que produz a predição de que algo acontece em uma certa ordem que não pode ser alterada sem repercussões em sua esfera. A condição de artifício, o reconhecimento de que não se trata de algo natural, mas instituído, permite-nos operar, intervir, interferir, perguntar, falar, fazer e dizer.

Poderíamos perguntar : por que sustentar qualquer forma cerimonial se ela representa uma ficção que sustenta uma ilusão? Por que sustentar qualquer forma cerimonial se ela representa uma ficção não sujeita a parâmetros científicos? Essa é a pergunta do desencantado subjugado por uma nova crença, uma nova ilusão, aquela que enuncia que "o real é racional, e todo o racional é real". (Lacan, 1960, 23 de março).

Essa ilusão tem seus efeitos devastadores quando é transmitida como máxima contemporânea e se expressa como regra que regula o mercado de consumo, pretendendo regular também os laços sociais. 


\section{Se nada é possível, tudo é possível.}

Quais são os efeitos dessa ilusão em relação ao suporte às novas gerações? Quais são os efeitos singulares e coletivos da renúncia ao suporte da inscrição da legalidade da cultura?

A partir do desenvolvimento da linguística e das pesquisas de LéviStrauss, os ritos e suas cerimônias constituem-se como expressões coletivas em que se põe em jogo a legalidade do inconsciente, que não é outra além da legalidade da linguagem. Os ritos em suas cerimônias conferem um marco simbólico ao real da experiência e, a partir daí, outorgam sustentação ao desdobramento imaginário no qual podemos ler as transformações expressas pelas variações de crenças em diferentes épocas, regiões, tradições mais ou menos arraigadas, mais ou menos sujeitas a suportar o movimento que as crenças provocam.

Crenças mais ou menos cruéis com meninos e meninas, que variam segundo os tempos, muitas delas duráveis, especialmente nas práticas sacrificiais em que os corpos infantis poderiam estar investidos de uma suposta maldade ou serem portadores de algum dano imaginário para a comunidade em questão ${ }^{10}$. Hoje, o sacrifício de uma grande quantidade de meninos e meninas tem formas mais sutis, porém não menos eficazes.

Ritos e rituais dão um lugar de ex-sistência ao real, entendido como o inatingível, o intocável, garantindo a permanência da lei como um vazio estrutural. O marco simbólico dá suporte à lei, sem-ser-a-lei, traduzindose em cerimônias que dão suporte às ficções que dele emanam.

Ao longo dos tempos, por meio do cerimonial que se monta e se sustenta na liturgia que cria o roteiro da cena, o ser humano encontrou um limite; conferiu um marco simbólico ao real da experiência (o nascimento, o sexo e a morte), às forças da natureza, à relação com os deuses e também criou formas de compensar as carências, o que lhe faltava, por meio do intercâmbio de bens. Nas formas cerimoniais se escrevem as regras que cada grupo humano estabelece para regular os intercâmbios.

Ainda que certas tendências da Academia tenham considerado este problema como algo que deva ser abandonado, especialmente pelos efeitos de sustentação de tradições que são indesejáveis, com o que concordamos, consideramos necessário recuperar sua lógica em relação ao mito e ao jogo já que, além das ideologias, pela sua operação metafórica e metonímica, eles refletem a lógica da linguagem no coletivo.

Ritos e rituais de passagem não foram abolidos. Muito pelo contrário, permanecem vigentes, ainda que deslocados dos cenários socioeducativos e religiosos que os validavam para os cenários comerciais e mercantis. Convidamos os leitores a refletir sobre a estrutura dos programas de televisão 
de maior rating como os produzidos por Tinelli, um apresentador da TV argentina, e outros, cujos formatos seguem formas cerimoniais ritualizadas de modo excessivamente estrito.

Também é surpreendente a pouca importãncia atribuída ao que, desde Bleger, na formação de psicólogos e profissionais de outras disciplinas, considerava-se definido e sustentado como "enquadre de trabalho", artifício não natural, disposto ao serviço de uma tarefa. Estamos interessados nas semelhanças e diferenças das cerimônias mínimas. Enquanto que um enquadramento de trabalho sinaliza um marco, delimita e estabelece diferenças, estará na habilidade de seu desenho a flexibilidade para abrir portas e maneiras de configurar cenários de trabalho; nas cerimônias mínimas, partimos de um recorte discursivo, de um dito, para depois recriar enquadres.

Nas cerimônias mínimas não se trata apenas do marco assinalado pela definição temporal e espacial, mas de que modo pode-se desenhar o cenário, o roteiro, os protagonistas, os lugares que façam possível o desenvolvimento dramático de cenas subjetivas e coletivas, a partir das quais os efeitos socioeducativos não resultem só em boas intenções.

Definir cerimônias mínimas significa delimitar um dito (valor simbólico); desenvolver seu cenário e sua estrutura dramática (desenvolvimento do imaginário). Ao fazê-lo, faremos uma operação de duplo jogo, faz̧er di- 
zer ao dito; interferir no devir metonímico conforme o caso, criando uma borda frente ao real.

De modo comum com o enquadre, uma cerimônia mínima não é per se natural, mas em todos os casos envolve uma criação e uma decisão. Isto é, nós as promovemos para que uma determinada tarefa possa se realizar. Fixar certas variáveis temporo-espaciais permite outorgar certa estabilidade e previsibilidade em um continuum. No entanto, nem sempre é possível começar uma tarefa apenas delimitando a data e a hora da realização. Este é um ponto de falha repetida nas reivindicações dos adultos quando se trata do tratamento de crianças instáveis.

Maud Mannoni (1982) inventou um nome muito interessante para isso - ela chamou de "instituição estourada", uma vez que a instituição não estava sustentada pela estreiteza dos horários, mas pelo arcabouço simbólico do discurso; pela presença de outros, dispostos a apoiar e veicular as mínimas possibilidades transferenciais que as crianças podiam ter à disposição.

O enquadre de trabalho transformado em cerimônias mínimas supõe o marco simbólico para o desenvolvimento de uma tarefa e, especialmente, para tornar possível a leitura da transferência que se apresenta; os intervalos que falam nos interjogos presença- ausência; as repetições e os significantes que aí se desenvolvem.

Sabemos o quanto as boas intenções rapidamente podem levar à de- cepção e ao fracasso quando se supõe que falar de "enquadre" ou de "instituição" se restringe à definição horária e espacial. Tal é o caso do "horário reduzido", baseado na diminuição do tempo de permanência das crianças na escola. Esse enquadre que em numerosos casos é solidário da sustentação do dispositivo disciplinar - perde sua possível eficácia quando está a serviço da sustentação da descrença de uma decisão excludente. Contudo, pode resultar daí uma hiância, um espaço vazio, para criar para uma criança condições para sua socialização e aprendizagem conforme o que ela mesmo possa ir tolerando na transferência com outros pelas cerimônias mínimas.

Como dissemos, nada é "bom" ou "mau" em si mesmo, mas trabalhar sobre o enquadre pode tornar possível o que de outro modo nem sempre o foi, na medida em que ele seja analisado e esteja disponivel ao serviço do acompanhamento de processos subjetivantes, isto é, socioeducativos, das crianças. Esse ponto é imperioso quando se trata de crianças "soltas", instáveis, com dificuldades de adaptação, rebeldes e desconfiadas, que estabelecem uma transferência mais violenta, desencadeada pelos efeitos do traumático que fala por atos sem palavras, tornando difícil seu suporte por parte dos adultos ritualizados, sem capacidade de jogo.

Analisemos um exemplo que ilustra como uma cerimônia mínima pode operar efeitos socioeducativos, 
quando uma professora decide sair do ritual da violência cotidiana, para abrir o jogo significante:

Uma professora do terceiro ano do Ensino Fundamental decide começar o dia de trabalho com a leitura de um conto para um grupo francamente barulhento. Decide fazer algo diferente com seu próprio mal-estar cotidiano. Pergunta-se como fazer para se colocar como condutora da turma. Deseja ser escutada, diz que não se dedicou à docência para sofrer diariamente. Decide começar a semana com uma surpresa. Chega à escola em uma segunda-feira, ingressa na sala deixando suas coisas na mesa. Não cumprimenta os alunos; as crianças entram alvoroçadas, o descontrole se aproxima. Diante dessa situação, pega um livro de sua pasta, dramatiza a cena e, em lugar do grito e da reprimenda costumeiros, dirige-se a eles em voz alta e em tom enérgico: "Era uma vez..." e começa a relatar-lhes o conto, não um qualquer, mas um mito escolbido que the agradava e intrigava. Olhares de surpresa... as crianças se entreolham, vão ficando caladas e se tranquilizam... A professora finaliza o relato, e acrescenta: a aula já começou. Diz o clássico "bom dia meninos" e, para sua surpresa, recebe um sonoro "bom dia". Alguns fazem comentários sobre o relato, outros não dizem nada. Após vários dias repetindo esta cena, um dos meninos the pede, "tia, conta um conto de terror". Ela responde que sim, que o procurará para o dia seguinte. Decide levar-lhes os Contos da Selva, de Horacio Quiroga. Entre a professora e os alunos abriu-se um espaço habilitante de circulação de ficções, relatos fantásticos, em suma, de outra cena.

\section{Cerimônias mínimas, função do Estado?}

Ainda que nos encontremos em tempos em que a legislação considera a criança como sujeito de direito, não devemos esquecer que uma criança não existe porque a lei assim o diz e estabelece, mas que a lei, enquanto código escrito, oferece o marco simbólico de referência e inscrição social. Uma criança existe quando ela é nomeada, identificada, amada, quando se olha para ela, quando se fala com ela mesmo que, aparentemente, ela não nos entenda; quando é registrada em cartório, recebendo um lugar nomeado na sociedade. Faž-se uma criança quando ela ingressa no desejo do Outro e ali se aloja.

A possibilidade para cada criança que chega a este mundo de poder escrever sua história e fazer parte de um coletivo social compete-nos inicialmente e durante os vários anos que os acolhemos. Muitas crianças são alojadas, há mais de um século, pelo circuito institucional não familiar e, para elas, as possibilidades de educação se apresentam limitadas - para algumas, lamentavelmente excludentes. Muitas crianças procuram hoje a presença desse marco institu- 
cional e não o encontram, chocandose com ideais de desinstitucionalização devastadores.

Neste sentido, as epistemes baseadas em "ilusões (psico) pedagógicas" (de Lajonquière, 2000) do dispositivo encarregaram-se de fortalecer a ideia que nos propomos questionar por meio da seguinte interrogação: quais são as formas cerimoniais necessárias para sustentar a socialização e a educação de uma criança deslocada de sua família ausente, carente ou impotente - em direção ao social e institucional?

A episteme que enuncia o educativo como social, e o esclarece na expressão socioeducativo, renova esta possibilidade e permite colocar no roteiro que liga o social com a educação a hiância onde possam emergir os efeitos de subjetivação.

Alienação-separação entre o Social e o Educativo localizam o interjogo possível para outras ficções além das dispostas pelas formas de exclusão dos outrora bastardos, órfãos, abandonados, crianças desligadas do social pela condenação de "inadaptadas", ainda que sujeitas ao consumo - inclusive de seus corpos - em suas múltiplas formas

Aqui, os circuitos de inscrição social cerimonial precisam ser especialmente considerados por seu valor simbólico e pelas ficções que os sustentam. Estar documentado ou não documentado não é apenas uma questão legal, moral ou econômica, mas trata-se de contar com um lugar mar- cado simbolicamente em uma linhagem familiar e social à qual cada nova criança tem o direito de pertencer em uma sociedade civilizada.

A partir do exposto, consideramos que devemos dirigir-nos para as formas cerimoniais que sustentamos e que fazem a produção de subjetividade contemporânea, entendendo que, enquanto pensamos que estamos operando na produção de subjetividade das crianças, isso nos produz. Esta afirmação expõe uma invariante histórica.

Produto das pesquisas que temos apresentado em textos anteriores (Minnicelli, 2000, 2004, 2005, 2008, 2010) esta é uma hipótese que nos permite posicionar-nos em relação ao que foi afirmado antes. Por ela comprovamos que, independentemente das épocas e culturas para as quais nos orientemos para seu estudo e análise, não é possível descrever e inscrever as crianças fora do universo simbólico da época, veiculado pela linguagem por meio de cerimônias, discursos e práticas falantes e silenciosas, que definem e posicionam as novas gerações em relação ao Outro... e de outros. Inclusive em nossa época.

Desde a Antiguidade, fundadora do pensamento ocidental, as noções de infância, de crianças, de meninos e meninas estão subordinadas às controvérsias presentes em enunciados míticos, filosóficos, religiosos, educacionais, legislativos, médicos, e acima de tudo, aos sistemas de crenças (divindades, espíritos malignos ou 
benignos) com relação às ficções que uma comunidade determinada formule sobre as crianças. Essas crenças foram determinando diversas práticas exercidas sobre as crianças, seus corpos e suas "almas", mais ou menos cruéis de acordo com os tempos.

Diante de certas correntes que se posicionam como se não fosse necessário fazer um sujeito, e fazer-se sujeito no campo do Outro, é preciso repetir o que já foi dito. Sabemos bem que a sustentação das novas gerações por parte das precedentes não acontece por geração espontânea, mas implica em uma irrenunciável tarefa humana. A violência que surge nos comportamentos infantis é evidência da frágil resistência que se oferece à tendência contemporânea da mercantilização das vidas humanas.

É por isso que, sabendo dos limites que nos são impostos, e justamente por eles, é necessário renovar a oferta de apoio da lei na configuração subjetiva. $\mathrm{Na}$ falta disso, fica claro que, quando as crianças têm que se virar sozinhas para encontrar tais marcos de referência em outros, geralmente em seus pares em condições semelhantes, subtendendo-os pela força, sem interpelação alguma por parte dos adultos, é somente a força policial que os captura quando o delito resulta em meio para uma nova institucionalização, nesse caso, policial e jurídico - institucional. E a roda volta a girar em seu único sentido.

A lógica mercantil tem sido configurada sobre as bases do dispositi- 
vo Moderno, acarretando como consequência a ilusão tentadora da lei do vale tudo sobre a regulação dos laços sociais e das instituições filiativas intergeneracionais. É a essa lógica à qual é imperativo oferecer resistência com a institucionalização da diferença, instituinte da infância.

Como consequência do exposto, surge então, como efeito de sentido, a noção de criança como consumidor, subordinando-as a epistemes que assinalam as mudanças tecnológicas e o mercado ou a ausência de família ou outras coisas, e as causas da emergência de tais comportamentos como monstros indestrutíveis. E ali ficam abandonados, à deriva, como se não fosse possível fazer mais nada. A história e as histórias de vida nos ensinam que uma vida viável é possível, mesmo com um nascimento em ambientes e condições desfavoráveis.

Se nos considerarmos parte deste problema, como protagonistas, podemos colocar em nossa perspectiva as margens de ação e intervenção possíveis, de tal maneira que, contemplando a singularidade do caso em relação a um certo coletivo social, seja possível operar e recriar laços ali mesmo onde a fronteira é apresentada como abismo - e para isso só se necessitam cerimônias mínimas.

Renovar a pergunta do caso ilustrado pode ser uma via interessante para retomar o fio emaranhado : a quem nos dirigimos quando falamos com uma criança / de uma criança / para uma criança / sobre uma criança?
Constatamos permanentemente de que modo, pelas cerimônias mínimas, pode-se limitar a distância com o macrossocial que tem como efeito impotência e incapacidade para fazer frente à complexidade de variáveis que atentam contra as condições de subjetivação, recuperando margens possíveis de intervenção investida de um papel social, seja este docente ou profissional.

Pode parecer ousado e irrisório sustentar esse conceito em tempos em que se espera do Estado - passivamente em muitos casos - a resolução dos grandes problemas que afetam a educação em geral, e os problemas das novas gerações em particular. Não se trata de uma proposta que deve ser abandonada, na medida em que devemos compreender que um dispositivo "reclama" quando percebe que se "desarticula" de cada uma das microcapilaridades dos nós que o configuram. Não há nenhum dispositivo que possa se sustentar se ao mesmo tempo não existe uma amplíssima rede de cerimônias mínimas que the outorguem credibilidade e sustentação. Voltemos aos casos apresentados: se os bebês não estão brincando, mas amotinando-se; se esconder o caderno de comunicações quando não estão presentes os destinatários das notificações transforma-os discursivamente em delinquentes, estamos crucificandoos a um destino sem jogo, que representa, em cada caso, a voz do Estado. 
Devemos ser claros sobre isto. Quando analisamos a educação das novas gerações, uma das primeiras premissas é não negar em absoluto a importância nem o papel do Estado. Porém, a ausência ou a presença do Estado se estabelece, também, por meio das cerimônias mínimas sustentadas por seus representantes.

O chamado Estado se apresenta como um aparelho complexo que vivemos como estrangeiro a nós mesmos; como um grande Outro longínquo que nunca cumpre nem responde à altura as mínimas expectativas. Porém, se desmontamos o novelo ver-nos-emos como parte desse mesmo novelo, do tecido que nos liga, na medida em que o representamos nas funções sociais que exercemos, e nas investiduras que o próprio Estado e suas formas de regulação nos outorgam como docentes, profissionais, diretores ou funcionários.

Ou seja, não podemos não ser parte do assunto ainda que apresentemos - e representemos - diferentes níveis de responsabilidade. Esperar a que outro resolva pode deixar-nos paralisados ante as pequenas - ainda que significativas - possibilidades de interferência na tendência mortificante do sistema. Sistema ao qual também pertencemos e pertencem nossas crianças, sejam filhos, sobrinhos ou netos, vizinhos ou amigos, alunos ou pacientes em todos os níveis. 


\section{Práticas socioeducativas, sua sustentação pelas cerimônias mínimas}

Seguindo a rede argumentativa apresentada até aqui, chegamos à hipótese que nos interessa continuar trabalhando. As práticas socioeducativas, através das cerimônias mínimas, constituem um ponto chave na possibilidade de análise e interferência daquilo que se apresenta como disposto e inamovível.

As cerimônias mínimas abrem ao jogo diante de práticas criptografadas e naturalizadas, tal como apresentamos apenas com fins ilustrativos: os exemplos podem se multiplicar.

As cerimônias mínimas são a chave para uma hiância, uma fenda, a partir da qual "entre" o dito e o feito possam relançar-se outros dizeres e outras formas de fazer. Ao mesmo tempo, são uma privilegiada unidade de análise na detecção dos modos de criptografia e naturalização que transportam algo de nefasto da história, tornando-a presente; permitindo outras significações frente a um campo de sentido através do qual se repete o inamovível dado e estabelecido.

Winnicott (1947/1998), psicanalista inglês, ofereceu-nos suas inquietações e experiências com o que foi denominado de "crianças carentes" ou "crianças anti-sociais" nos tempos de guerra e pós-guerra. Recomendamos a leitura e a discussão do texto Deprivación y delinqüência, especialmente

318 Estilos da Clínica, 2011, 16(2), 294-323 
o capítulo "Manejo residencial como tratamiento para niños difíciles" editado por Paidós.

Por sua vez, desde o início do século XX, em suas Obras escolbidas, Vigotsky se perguntava sobre as "crianças dificilmente educáveis", destacando o lugar e desafio que estas crianças representavam como sujeitos para os docentes e profissionais, desafios esses renovados pelos questionadores das formas possíveis de fazer advir a socialização e a educação.

Certos princípios que orientaram intervenções docentes e profissionais devem ser certamente questionadas quando se pretende renovar a possibilidade de socialização e educação. Especialmente aqueles que estabeleceram a funcionalidade familiar como uma normatização moral das relações, fixando linhas divisórias estritas, que ainda persistem, para nomear as diferenças com base nas disfuncionalidades, nas falhas, nas carências e ausências com a consequente necessidade de "reabilitações", sustentadas em ficções que resultaram extremamente eficazes ao longo de décadas - e continuam marcadas em cerimônias mínimas sustentadas pelos agentes de intervenção direta.

Critérios que ainda persistem sem questionamento e se instituem em relatórios sociais, psicológicos e psicopedagógicos, repetindo-se uma e outra vez ao longo dos anos de uma criança que transita por cenários judiciais, escolares, institucionais ou por qualquer organização que envolva atuações com eles ${ }^{11}$. Em muitos casos, disfarçados como texto de uma nova lei, contradizem-se imediatamente nas prescrições e/ou argumentações que formulam.

Nem toda prática intencionalmente concebida como socioeducativa cumpre seu propósito, e, além disso, muitas vezes não se trata de uma prática concreta, mas de restabelecer a função socioeducativa que os adultos têm com as crianças. Essa função não se encaixa em desenhos de programas prolixos, porém é a ela que nos dirigimos e é por ela que atuamos. Nesse sentido, consideramos importante distinguir o que implica o sofrimento desnecessário gerado pelas condições de fechamento trágico com referência ao mal-estar próprio do viver.

Cerimônias minimas podem constituir a chave para encontrar a diferença, especialmente porque elas se localizarão no óbvio, sempre tão próximo e tornado invisível para a nossa margem de protagonismo e ação, tal como no caso da professora que decide criar uma passagem entre o fora e o dentro de sua classe ao iniciar o dia com o "Era uma veそ... e entrou por uma porta e sain por outra e essa 
aula já começou". Somos nós que criamos e recriamos as condições que fazem laço ou não.

Concluímos afirmando que as cerimônias minimas são inventadas, isto é, não são naturais nem fazem parte da organização social e institucional normatizada. Por meio delas podemos ser protagonistas da cena que nos preocupa e ocupa, do tempo que dará lugar a outras ficções, outros jogos de verdade além dos já estabelecidos; sem mais, será possível fazer do dito, outros dizeres.

Qualquer forma cerimonial mínima poderá ser iniciada pela renovação dos questionadores da própria implicação biográfica nas intervenções, no instante em que se decide situar-se como adultos frente às crianças, para dar lugar à palavra e à escuta do sujeito, de modo substantivo e essencial, razão pela qual consideramos necessária - ainda que a admitamos como não prescriptível - a reflexão ética.

\section{MINIMAL CEREMONIES}

\section{Abstract}

In this paper, from the perspective of Psychoanalysis and Education, we will approach Minimal Ceremonies as a device suitable for clinico-social intervention and research, a metaphorical operator which allows us to create subjectificating conditions of possibility in different social, educational, institutional and community settings.

Index terms: psychoanalysis; education; device; minimal ceremonies; socio-educational practices. 


\section{Dossiê}

\section{CEREMONIAS MÍNIMAS}

\section{RESUMEN}

En este trabajo, desde la perspectiva de Psicoanálisis y Educación, abordaremos a las ceremonias mínimas como dispositivo apto para la intervención y la investigación clínico-social, operador metafórico que nos permite crear condiciones de posibilidad subjetivantes en diferentes escenarios sociales, escolares, institucionales, comunitarios.

Palabras clave: psicoanálisis; educación; prácticas socio-educativas.

\section{REFERENNCIAS}

Agamben, G. (2003). Infancia e historia. Buenos Aires: Adriana Hidalgo.

Agamben, G. (2004). Estado de excepción. Buenos Aires: Adriana Hidalgo.

Bourdieu, P. (1985). Los ritos de institución. ¿Qué significa hablar? Torrejón de Ardoz, Espanha: Akal, D. L.

Lajonquière, L. (2000). Infancia e ilusión (psico)pedagógica. Buenos Aires: Nueva Visión. Foucault, M. (1989). Vigilar y castigar: nacimiento de la prisión. Buenos Aires: Siglo XXI Editores.

Freud, S. (1995). Más allá del principio de placer. In S. Freud, Obras completas (J. L. Etcheverry, trad., Vol. 18, pp 1-62). Buenos Aires: Amorrortu. (Trabalho original publicado em 1920)

Freud, S. (1995). El malestar en la cultura. In S. Freud, Obras completas (J. L. Etcheverry, trad., Vol. 21, pp. 215-222). Buenos Aires: Amorrortu. (Trabalho original publicado em 1930)

Lacan, J. (1995). El seminário, libro 1: los escritos técnicos de Freud. 1953-1954. Buenos Aires: Paidós.

Lacan, J. (1992). El seminário, libro 2: el yo em la teoría de Freud y em la técnica psicoanalitica, 1954-1955. Buenos Aires: Paidós.

Legendre, P. (1996). El inestimable objeto de la transmisión: estudio sobre el principio genealógico em Occidente. México: Siglo XXI Editores.

Mannoni, M. (1982). Un lugar para vivir. Barcelona, Espanha: Grijalbo. (Trabalho original publicado em 1976).

Minnicelli, M. (2000). História pública. Segredos privados. Estilos da Clínica. Revista sobre a Infância com Problemas, 5(9), 152-160.

Minnicelli, M. (2004a). Infancias públicas. No bay Derecho. Buenos Aires: Noveduc.

Minnicelli, M. (2004b). De límites, confines y fronteras. Notas sobre el problema de los límites, de la autoridad y la responsabilidad. In M. Minnicelli (Org.), Intersecciones entre clínica y escuela (pp. 6-17). Buenos Aires: Noveduc.

Minnicelli, M. (2005, abril). Peligro, niños em la escuela. Notas sobre os imaginarios que sostienen la moral de niño peligroso. Colección ensayos y experiências, 58 , 106-122.

Minnicelli, M. (2008a). Infancia e institución(es): escrituras de la ley. In M. Minnicelli (Org.), Infancia e institución(es) (pp. 13-48). Buenos Aires: Noveduc.

Minnicelli, M. (2008b).Infancia, legalidad y juego en la trama del lenguaje. In M. Minnicelli (Org.), Infancia, legalidad y juego em la trama del lenguaje (pp. 17-32). Buenos Aires: Noveduc. 
Minnicelli, M. (2010). Infancia sen estado de excepción. Derechos del niño y psicoanálisis. Buenos Aires: Noveduc.

Vigotsky, L. S. (1990). Obras escogidas. (Vol. 5). Madrid: Visor.

Winnicott, D. (1998). Deprivación y delincuencia. Buenos Aires: Paidós. (Trabalho original publicado em 1947)

\section{NOTAS}

1 Este escrito dá continuidade ao trabalho "Escrituras de la ley en la trama social. Ensayo sobre la relación entre dispositivos, ceremonias minimas y prácticas profesionales" Revista Pilquen • Secção Psicopedagogia • Año X • No 5, 2008.

2 Seguimos neste sentido a definição de Nasio (1994). " pode também ser traduzido por "significantes"; "significantes recalcados"; "cadeia de significantes reprimidos". O dito é algo que tem valor de ato.

3 Cerimônia (latim caerimonia, -ae, caráter! sagrado, veneração, respeito, culto, cerimônia) s. f. Cerimônia (latim caerimonia, -ae, caráter! sagrado, veneração, respeito, culto, cerimônia) s. f.. Forma exterior e solene de celebração de um culto religioso ou profano. = RITO, SOLENIDADE. Manifestação mais ou menos solene com que se celebra um acontecimento da vida social. Cada uma das formalidades rituais. Padrão convencional de comportamento que se emprega onde a familiaridade não existe. = ETIQUETA, PROTOCOLO. Mal-estar proveniente da necessidade de ser cerimonioso.

4 Não desenvolveremos aqui a distinção que Lacan realiza entre "ato" e "acting", deixando o assunto pendente porque que requer outras distinções precisas.

5 A autora diz "colorín, colorado...", expressão com a que terminam os contos em castelhano. (N. do T.).

6 Os efeitos desta tendência também podem ser encontrados na suspensão de qualquer forma cerimonial em cenários sociais 
nos quais são esperadas; como o caso de citações judiciais nas quais os oficiais de justiça, e inclusive certos profissionais, não sustentam forma cerimonial alguma, não se apresentam nem por seus nomes nem por suas funções sociais ante os implicados pela instância que opera como marco simbólico de referência social.

7 Para ampliar este assunto ver Minnicelli, M. "Escrituras de la ley en la trama social. Ensayo sobre la relación entre Dispositivos, ceremonias minimas y prácticas profesionales" Revista Pilquen • Secção Psicopedagogia • Año X • No 5, 2008, 2008 disponible en http://www.revistapilquen.com.ar/NE_Psicopedagogia.pdf

8 Uma descrição mais ampla do caso se encontra em Infancia Pública. No hay derecho. (Minnicelli 2004)

9 A questão da apresentação pessoal desajeitada e o estado geral das crianças são analisados em outro lugar. (Minnicelli, 2004)

10 Mereceria um desenvolvimento à parte, ante o qual não nos deteremos, o problema dos rituais sacrificiais, problema trabalhado pelo antropólogo René Girard (1997) que critica com solvência Gerez Ambertín (2008).

11 Ver Minnicelli, M. "De límites, confines y fronteras. Notas sobre el problema de los límites, de la autoridad y la responsabilidad". Em Intersecciones entre clínica y escuela. Buenos Aires: Noveduc, 2004b (55).

mercedes_minnicelli@hotmail.com

Recebido em maio/ 2011.

Aceito em julbo/ 2011. 